Nevşehir Bilim ve Teknoloji Dergisi (2021), 10(2) 85-91

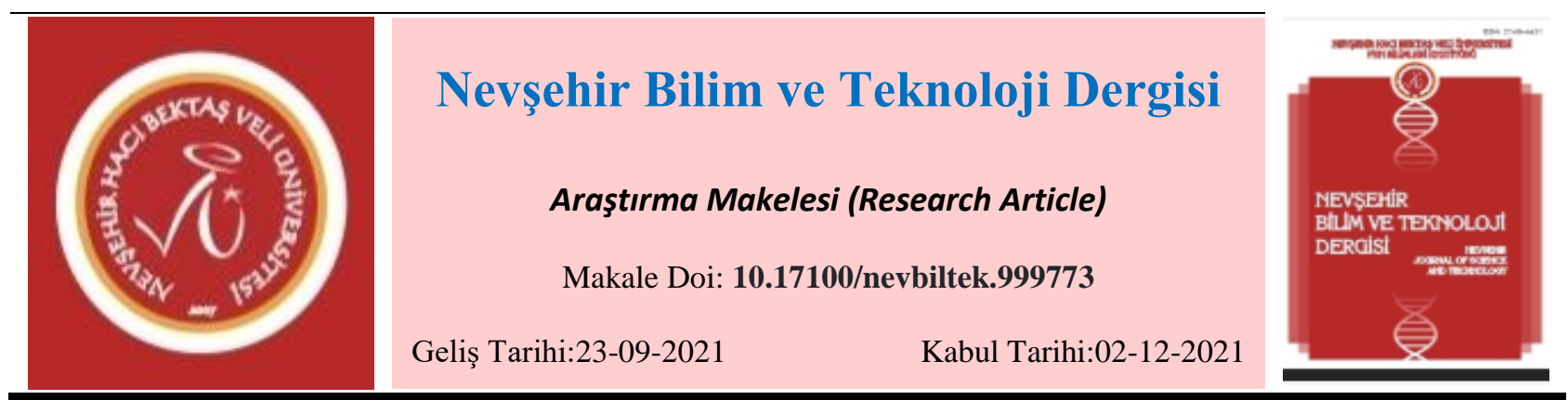

\title{
Döküm Mg+\%15Al12Si alaşımının mikroyapı ve sertlik incelemesi
}

\author{
Bünyamin ÇİÇEK*, Yavuz SUN ${ }^{2}$ \\ ${ }^{1}$ Hitit Üniversitesi, Teknik Bilimler Meslek Yüksekokulu, Makine ve Metal Teknolojileri, Çorum \\ ORCID ID: 0000-0002-6603-7178 \\ ${ }^{2}$ Karabük Üniversitesi, Mühendislik Fakültesi, Metalürji ve Malzeme Mühendisliği, Karabük \\ ORCID ID: 0000-0002-7336-5591
}

Öz

Bu çalışmada Mg metaline Al ve Si elementlerinin ilavesi ile bir döküm yapılmıştır. Döküm sırasında atmosfer kontrollü bir firın kullanılmıştır. Potaya saf $\mathrm{Mg}$ metaline ilave olarak ağırlıkça \% $15 \mathrm{Al}_{12} \mathrm{Si}$ ingot alaşımı eklenmiştir. Elde edilen alaşım homojenleştirme 1sıl işlemi sonrasında numune haline getirilmiştir. Mg-Al-Si üçlü bileşiği şeklinde hazırlanan alaşıma döküm sonrası SEM ile mikroyapı incelemesi yapılmıştır. Ek olarak alaşıma elementel analiz uygulanmıştır. Son olarak alaşım Vickers tipinde sertlik testi ölçümüne alınmıştır. Elde edilen verilerle alaşım mikro yapısında oluşan intermetalik fazların dağı̆lımı ve yapıları incelenmiştir. Sonuç olarak $116 \mathrm{HV}$ seviyesinde sertlik gösteren seramik partikül takviyeli bir kompozit malzeme üretilmiştir.

Anahtar Kelimeler: Magnezyum; döküm; alaşım; mikroyapı, kompozit.

\section{Microstructure and hardness investigation of cast Mg-Al-Si alloy}

\begin{abstract}
In this study, a casting was made with the addition of $\mathrm{Al}$ and $\mathrm{Si}$ elements to $\mathrm{Mg}$ metal. Atmosphere controlled furnace was used during casting. In addition to the pure $\mathrm{Mg}$ metal, $15 \%$ by weight $\mathrm{Al}_{12} \mathrm{Si}$ ingot alloy was added to the crucible. The obtained alloy was sampled after homogenization heat treatment. After casting, the microstructure analysis of the alloy prepared in the form of Mg-Al-Si ternary compound was carried out by SEM. In addition, elemental analysis was applied to the alloy. Finally, the alloy was measured in Vickers type hardness test. The distribution and structures of the intermetallic phases formed in the alloy microstructure were investigated with the obtained data. As a result, a ceramic particle reinforced composite material with a hardness of $116 \mathrm{HV}$ was produced.
\end{abstract}

Keywords: Magnesium; cast; alloy; microstructure, composite.

*Sorumlu yazar: cicekbunyamin78@gmail.com 


\section{Giriş}

Yoğunluk değerinin düşük olması sebebiyle Magnezyum ( $\mathrm{Mg}$ ) birçok alanda kullanılan bir metaldir. Ancak Mg elementinin düşük yoğunluğu yanı sıra düşük mukavemet ve sertliği bu elementin alaşımlarını ön plana çıkarmıştır. Mg alaşımları literatürde son yıllarda biyo, uzay ve savunma gibi alanlarda birçok farklı özellikte kullanılmaktadır. Bu kullanım durumlarında saf $\mathrm{Mg}$ yerine birçok element ile alaşımlandırılmış malzemeler kullanılmaktadır $[1,2]$.

Mg elementi genelde $\mathrm{Al}, \mathrm{Si}, \mathrm{Ca}, \mathrm{Mn}, \mathrm{RE}$, vb. elementlerle alaşım halini almaktadır. $\mathrm{Mg}$ alaşımları standartlara bağlı olarak farklı alaşım elementlerinde farklı harflerle isimlendirilerek kullanılmaktadır ( $\mathrm{Al}=\mathrm{A}, \mathrm{Si}=\mathrm{S}, \mathrm{Ca}=\mathrm{X}, \mathrm{Mn}=\mathrm{M}$ gibi). Örneğin AZ91 alaşımında \%9 Al bulunurken \%1 oranında $\mathrm{Zn}$ yer almaktadır [2-4].

Saf Mg metaline eklenen alaşım elementleri; genelde termal etkiler altında Mg ile alaşım elementi arasındaki denge diyagramlarına göre farklı bileşikler oluşturmaktadır. İkili denge diyagramları yanında üçlü ve daha fazla element ile oluşturulan denge diyagramları da mevcuttur. Elementler arası tepkimelerle oluşan bu fazlar $\alpha-\mathrm{Mg}$ içerisinde dağılmış $\beta$-fazında ve farklı geometrilerde yapılar oluşturmaktadır. Örneğin bir $\mathrm{Mg}$-Al alaşımında sıklıkla $\beta$-faz olarak $\mathrm{Mg}_{17} \mathrm{Al}_{12}$ fazı oluşurken bu faz bir ağ formasyonunda ve tane sınırlarında bir intermetalik olarak yer almaktadır. Bir Mg-Si alaşımında ise genelde oluşan $\beta-\mathrm{Mg}_{2} \mathrm{Si}$ fazı partikül şeklinde ve çok sert bir formda ( $\mathrm{Si}$ elementinin etkisiyle bir seramik fazı) oluşmaktadır. Böylece alaşım elementlerinin ilavesi ile Mg saf özelliklerinden çok farklı sonuçlar göstermekte ve birçok alanda daha kullanılabilir hale gelmektedir. Bunların sonucu olarak fazların durumu ve geometrik yapıları dikkate alınarak malzemeler alaşım yerine kompozit olarak da adlandırılmaktadır [5-8].

Bu çalışmada AS serisi olarak isimlendirilen ve Mg metaline $\mathrm{Al}$ ve Si elementlerinin ilavesi ile oluşturulan bir alaşım üretilmiştir. Bu çalışmanın amacı oluşan fazların durumları ile bir kompozit yapının elde edilmesidir. Bu çalışmada ağırlıkça $\% 85 \mathrm{Mg}$ elementi ile $\% 15 \mathrm{Al}_{12} \mathrm{Si}$ alaşımı-bir döküm potasına eklenmiştir. Atmosfer kontrollü bir firında gerçekleştirilen döküm işlemi sonrasında numunelere mikroyapı durumları için SEM incelemesi, elementel analiz için EDX-XRF ve sertlik testi uygulanmıştır. Sonuç olarak AS14-1 alaşımı üretilmiş ve temel verileri elde edilmiştir. Rapor edilen sonuçlara göre yapı, bu çalışmanın amacında barınan metal matrisli seramik takviyeli bir kompozit olarak üretilmiştir.

\section{Materyal ve Metot}

$\mathrm{Bu}$ çalışmada ilk basamakta döküm işlemi $\mathrm{CO}_{2}+\mathrm{SF}_{6}$ karışım gazı ile ortam oluşturulmuş bir atmosfer kontrollü firında yapılmıştır. İlk olarak potaya $\mathrm{Mg}$ metali şarj edilmiş ve ergime sıcaklığında ilave alaşım $\left(\mathrm{Al}_{12} \mathrm{Si}\right)$ yapıya eklenmiştir. Sıvı metal yüzeyinde cüruf oluşturması için koruyucu flaks [9] yapıları ilave edilmiştir. Döküm firınında "in$s t u$ " sistemle seramik bir kapatıcı kullanılmışıı. Fırın sıcaklığı $740^{\circ} \mathrm{C}$ seviyelerinde iken seramik kapatıcı açılarak sıvı metal kalıba aktarılmıştır. Çelikten imal edilen silindirik bir iç boşluğa sahip bir kalıp kullanılmıştır. Çelik kalıp döküm işlemi öncesinde ani soğuma etkisi oluşmaması için $350^{\circ} \mathrm{C}$ sıcaklıkta tutulmuştur. Kalıp iç boşluğu yine aynı karışım gazı ile doldurulmuştur. Kalıp içerisinde oda sıcaklığına kadar soğutulan döküm ürünü tekrar firına alınarak $400^{\circ} \mathrm{C}$ sıcaklıkta 6 saat kadar homojenleştirme için firında bekletilmiştir. Homojenleştirme sonrası oda sıcaklı̆̆ına kadar serbest şekilde soğutulmuştur ve $20 \mathrm{~mm}$ çapında çubuk numuneler üretilmiştir. Dökümü yapılan malzemelerin ve elde edilen alaşımların makro resimleri Şekil 1'de verilmiştir. 


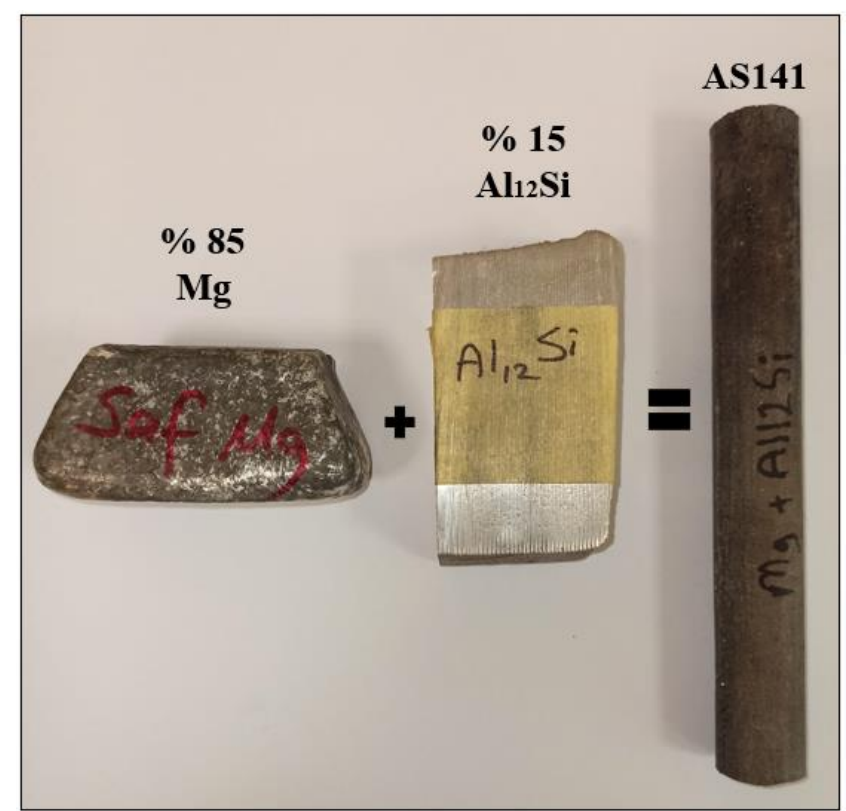

Şekil 1. Döküm malzemeleri ve yeni alaşıma ait makro görüntüler

İkinci aşamada elde edilen yeni alaşım ( $\left.\mathrm{Mg}+\mathrm{Al}_{12} \mathrm{Si} / \mathrm{AS} 14-1\right)$ numune hazırlığına alınmıştır. SEM incelemesi için yapı klasik metalografik hazırlığa tabi tutulmuş ve \%5 Picral (pikrik asit + alkol) reaktifi ile dağlanmıştır [6, 10]. Dağlanan yüzeyden farkı büyütmelerde görüntüler alınmıştır. SEM cihazında bulunan EDX analizi ile farklı fazların elementel analizleri incelenmiştir. Ayrıca numunenin XRF analizi de yapılmıştır.

Deneylerin son aşamasında ise alaşıma 1000gr yük altında 10 s süre ile Vickers sertlik testi uygulanmıştır. Sertlik testi 5 ölçüm olarak ve batma ucu izleri (d) arasındaki minimum mesafe (>6d) takip edilerek yapılmıştır [11]. Elde edilen 5 değerin ortalaması alınarak rapor edilmiş̧ir. Alaşım elementleri ile yapıda oluşan intermetalik fazların sertlik değerine etkisi incelenmiştir. Batma ucu izi fotoğraf olarak alınmış ve görüntü analizi ile kırılma tokluğu yorumları yapılmıştır.

\section{Bulgular}

Üretilen AS14-1 alaşımı SEM incelemesine alınmış ve mikro yapılar elde edilmiştir. Seramik partiküllerin ve intermetalik yapıların takibi için farklı büyütmelerde görüntüler Şekil 2'de verilmiştir.
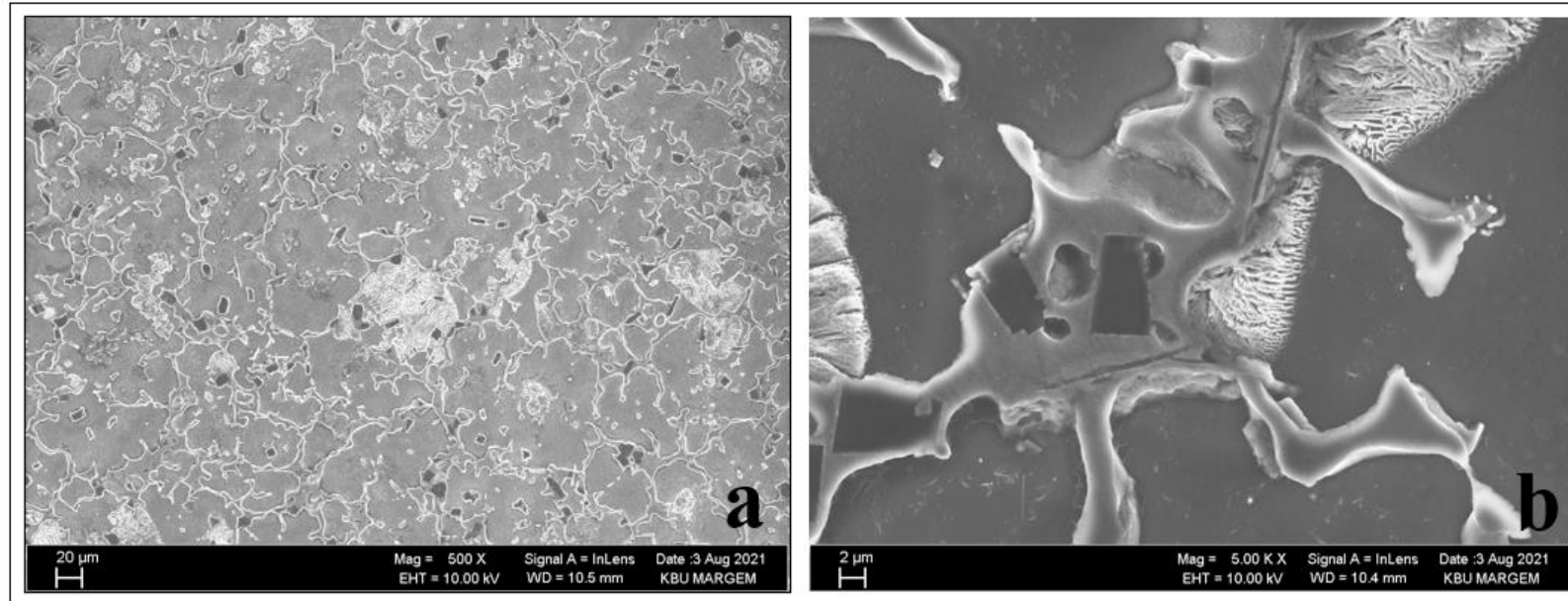

Şekil 2. Alaşıma ait mikroyapı görüntüleri (a) 500x büyütme ve (b) 5000x büyütme

Mikro yapı incelemesi sonrasında SEM cihazında alınan EDX taraması sonrası elde edilen analiz sonuçları Şekil 3 ve Tablo 1'de verilmiştir. Tablo 1'e ek olarak numunenin XRF sonuçları da eklenmiştir. Şekil 3'te Şekil 2b'de verilen yüksek büyütme görüntüsü üzerinden oluşan fazların literatür temelli işaretlemeleri yapılmıştır $[6,8,12]$. Buradan yola 
Nevşehir Bilim ve Teknoloji Dergisi (2021), 10(2) 85-91

çıkarak yapıda $\alpha-\mathrm{Mg}$ temel matrisinin yanı sıra intermetalik yapılar oluşmuştur. İntermetalik yapılar $\mathrm{Mg}$ - $\mathrm{Al}$ arasında $\mathrm{Mg}_{17} \mathrm{Al}_{12}$ şeklinde ve $\mathrm{Mg}$-Si arasında $\mathrm{Mg}_{2} \mathrm{Si}$ formunda meydana gelmiştir. Ayrıca $\mathrm{Mg}_{17} \mathrm{Al}_{12}$ fazı yapıyı örümcek ağı formasyonunda sarmalarken $\mathrm{Mg}_{2} \mathrm{Si}$ yapısı partiküller halinde homojen şekilde dağılmıştır. $\mathrm{Mg}_{2} \mathrm{Si}$ partikülleri genelde $\mathrm{Mg}_{17} \mathrm{Al}_{12}$ fazı içerisinde veya temas şeklinde oluşmuştur. Son olarak elementel analiz ve mikroyapı görüntüleri incelendiğinde $\alpha-\mathrm{Mg}$ içerisinde dağılmış Al elementinin varlığı izlenmiştir.

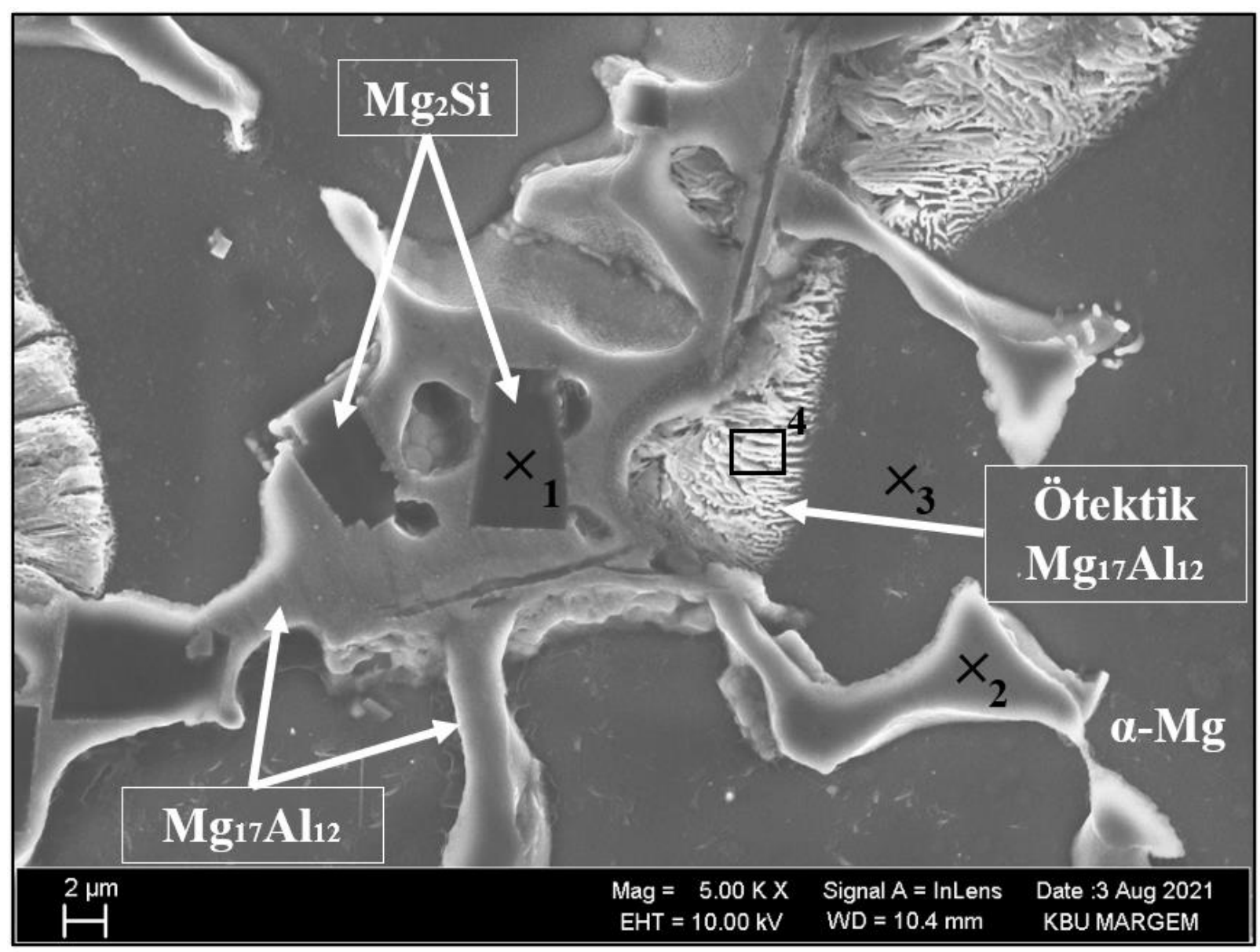

Şekil 3. Yüksek büyütmede fazların durumu ve EDX analiz bölgeleri

Tablo 1. EDX analiz bölgelerinde elementel oranlar ve XRF sonucu

\begin{tabular}{cccc}
\hline EDX No & Mg & Al & Si \\
$\mathbf{1}$ & 51,51 & 0,41 & 48,08 \\
$\mathbf{2}$ & 61,74 & 38,25 & 0,01 \\
$\mathbf{3}$ & 98,13 & 1,82 & 0,05 \\
$\mathbf{4}$ & 76,01 & 23,65 & 0,34 \\
\hline XRF & 84,33 & 14,42 & 1,25 \\
\hline
\end{tabular}

SEM ve EDX incelemeleri sonrasında numuneye sertlik testi uygulanmıştır. Sertlik testi sonucunda ortalama değer $116 \mathrm{HV}_{1} \pm 8$ olarak tespit edilmiştir. Sertlik testi sonucunda oluşan batma ucu izi üzerinden iz köşegenlerinde oluşan veya oluşabilecek çatlakların analizi ile kırılma tokluğu hesaplamaları yapılması bilinen bir yöntemdir [13-15]. Mikro sertlik test yönteminde ve $\mathrm{Mg}$ temelli alaşımların sertlik ölçümünde genelde düşük ağırlıklarda ölçüm yapılmaktadır. Ancak bu çalışmada bir Mg alaşımı için yüksek olan 1000 gr. yük kullanılmıştır. Sertlik testinde yüksek yük miktarının kullanılmasıyla sert seramik takviyesinin yapıdaki etkisinin görülmesi amaçlanmıştır. Bu amaçla sertlik testi sonrasında elde edilen bir batma ucu izi Şekil 4’te verilmiştir. Yüksek yük miktarı sonucunda oluşan Şekil 4 incelediğinde iz köşegenlerinde sertlik testi sonrasında bir çatlak formu izlenmemiştir. 


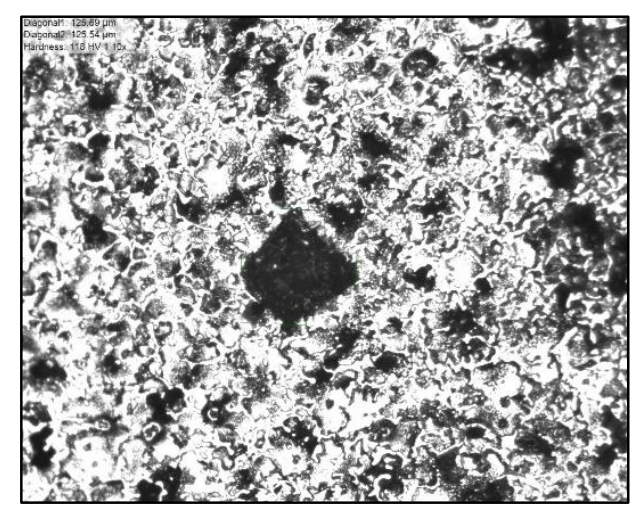

Şekil 4. Vickers sertlik batma ucu izi

\section{Tartışma ve Sonuç}

Mg-Al-Si üçlü alaşımından elde edilen temel incelemeleri kapsayan çalışmamızda SEM, EDX, XRF ve sertlik incelemesi bu raporda sunulmuştur.

SEM incelemesi sonucunda elde edilen mikro yapılarda farklı faz formasyonları görülmüştür. İlk olarak yapıda koyu kontrastta bulunan $\alpha-\mathrm{Mg}$ yapısı matris faz olarak bilinmektedir. Çalışmamız bu fazın durumu ile ilgili tutarlılık göstermiştir [8, 16-18].

İncelemeler sonucunda görülen $\mathrm{Mg}_{17} \mathrm{Al}_{12}$ fazı ise literatürle benzer yönde yapıda homojen şekilde dağılmıştır. Bunun yanı sıra EDX incelemelerinde bu fazın hem ötektik hali hem de ötektik sonrası hali izlenmiştir. Bu faz alaşımda bir ağ formunda iskelet bir yapı şeklinde oluşmuştur. Literatürde benzer alaşımların içerdiği alaşımlar göz önünde bulundurulduğunda çalışmamız benzer sonuçlar vermiştir. Bu faz aynı zamanda intermetalik formda oluştuğu için sertlik değerini arttırdığg bilinmektedir [6, 10, 12, 19].

$\mathrm{Mg}-\mathrm{Si}$ arasında oluşan $\mathrm{Mg}_{2} \mathrm{Si}$ fazı ise yapıda köşeli partiküller şeklinde oluşmuştur. Bazı çalışmalarda bu fazın Si temelli bir yapı olduğu için seramik olarak değerlendirilmesi yapılmıştır [20]. Bu yönden düşünüldüğünde yapı metal matrisli ve seramik partikül takviyeli bir kompozit olarak değerlendirilmiştir [20, 21]. Ayrıca bu faz literatürde çok sert bir faz olarak bilinmekte ve yaklaşık 1000 HV kadar sertlik göstermektedir. Böylece yapıda sertlik değerini arttıran bir değişken olarak bulunmaktadır $[6,8,10,17]$.

Elementel analiz sonuçlarına bakıldığında ise farklı fazlar elementel oranları karşılamaktadır. Ayrıca XRF sonucunda döküm başlangıcında planlanan elementel oranların (\%85+\%15) sağlandığı görülmüştür. Böylece döküm aşamasından son aşamaya kadar elementel oranlar başarılı şekilde sonuçlandırılmıştır.

Son olarak yapıdan alınan sertlik değerlerine bakıldı̆̆ında sertlik ortalama değerinin 116 HV olduğu görülmüştür. Temel bir saf Mg metalinin sertlik değeri düşünüldüğünde 50-60 HV sertlik oranının intermetalik yapıların etkisiyle 116 HV seviyesine çıktığı izlenmiştir [2, 5, 6, 8]. Böylece oluşan fazların yapının sertliğini arttırdığı görülmüştür.

Kırılma tokluğu; çatlak içeren veya çatlak oluşturmaya yatkın malzemelerde kırılmaya direnme yeteneği olarak tanımlanmaktadır. Kırılma tokluğu seviyesini ölçmek için bir çok yöntem mevcuttur [15, 22]. Sert ve kırılgan yapıların veya sert kaynaklı malzemelerin sertlik izi köşegenlerinde oluşabilecek çatlak formu kırılma tokluğu seviyesini ve durumunu açıklamaktadır [14, 22]. Bu çalışmada ise sertlik batma ucu izi görüntüsünden yola çıkarak elde edilen temel sonuca göre malzemenin kırılma tokluğu üzerine sert seramik yapılar etkili değildir. Çatlak formunun oluşmaması ile bu sert yapıların alaşımın kırılma tokluğunu etkilemediği sonucuna varılmaktadır. Böylece yapıda oluşan sert seramik temelli fazın kırılma tokluğunu düşürecek kadar etkili olmadığı görülmüştür [13-15, 22]. 
Nevşehir Bilim ve Teknoloji Dergisi (2021), 10(2) 85-91

$\mathrm{Bu}$ çalışmanın genel sonucu olarak üretilen AS14-1 alaşımının temel mikroyapı özellikleri ve sertlik değerleri rapor edilmiştir. İntermetalik yapıların dağılımları, tipleri ve elementel analizleri incelenmiştir. Mg-Al-Si üçlü faz diyagramı altında oluşan $\mathrm{Mg}_{17} \mathrm{Al}_{12}$ ve $\mathrm{Mg}_{2} \mathrm{Si}$ fazları yapıda izlenmiştir. Böylece seramik partikül takviyeli metal matrisli bir kompozit malzemenin döküm yöntemi ile üretimi gerçekleştirilmiştir.

\section{Teşekkür ve Katkı Beyanı}

Çalışmanın hazırlanması aşamasında yazarlar; B.Ç.: Deneyin düzeneğinin hazırlanması, laboratuvar çalışmaları, raporlama Y.S.: Raporlama ve yorumlama görevlerinde bulunmuşlardır. Çalışmanın hazırlanmasında katkı sağlayan Karabük Üniversitesi Demir Çelik Enstitüsü MARGEM laboratuvarına teşekkür ederiz.

\section{Kaynaklar}

[1]. Froes, F., D. Eliezer, and E. Aghion, "The science, technology, and applications of magnesium", The Journal of The Minerals, Metals \& Materials Society (TMS), 50, 30, 1998

[2]. Mordike, B. and T. Ebert, "Magnesium: properties-applications-potential", Materials Science and Engineering: A, 302, 37-45, 2001

[3]. Wang, Q., et al., "Effect of Sb on the microstructure and mechanical properties of AZ91 magnesium alloy", Metallurgical and Materials Transactions A, 32, 787-794, 2001

[4]. Unal, M., An investigation of casting properties of magnesium alloys, in Metallurgical Engineering. 2008, Gazi University: Ankara, Turkey. p. 138.

[5]. Chakraborti, N. and H. Lukas, "Thermodynamic optimization of the Mg-Al-Si phase diagram", Calphad, 16, 79-86, 1992

[6]. Çiçek, B., H. Ahlatçı, and Y. Sun, "Wear behaviours of $\mathrm{Pb}$ added Mg-Al-Si composites reinforced with in situ Mg2Si particles", Materials \& Design, 50, 929, 2013

[7]. Miao, J., et al., "Interphase boundary segregation of silver and enhanced precipitation of Mg17Al12 Phase in a Mg-Al-Sn-Ag alloy", Scripta Materialia, 154, 192-196, 2018

[8]. Korgiopoulos, K., B. Langelier, and M. Pekguleryuz, "Mg17Al12 Phase Refinement and the Improved Mechanical Performance of Mg-6Al alloy with trace Erbium Addition", Materials Science and Engineering: A, 141075, 2021

[9]. Çiçek, B., "Mg2Si Partikül Takviyeli Mg Alaşımlarının Aşınma ve Korozyon Özelliklerinin İncelenmesi", $\boldsymbol{K} \ddot{\boldsymbol{U}}$ Fen Bilimleri Enstitüsü, Yüksek Lisans Tezi, 2011

[10]. Çiçek, B. and Y. Sun, "A study on the mechanical and corrosion properties of lead added magnesium alloys", Mater. Design, 37, 369, 2012

[11]. Herrmann, K., Hardness testing: principles and applications. 2011: ASM international.

[12]. Kannan, M.B., E. Koc, and M. Unal, "Biodegradability of $\beta$-Mg17Al12 phase in simulated body fluid", Materials letters, 82, 54-56, 2012

[13]. Anstis, G., et al., "A critical evaluation of indentation techniques for measuring fracture toughness: I, direct crack measurements", Journal of the American Ceramic Society, 64, 533-538, 1981

[14]. Roebuck, B., et al., Palmqvist toughness for hard and brittle materials. 1998: National Physical Laboratory.

[15]. TOPUZ, P., et al., "Borlanmış AISI 316 Üzerinde Oluşmuş FexB Tabakalarının Kırılma Tokluklarının İncelenmesi", Journal of Steel Research and Development, 12, 16, 2020

[16]. Elen, L., et al., "Effects of alloying element and cooling rate on properties of AM60 Mg Alloy", Materials Research Express, 2019 
[17]. Cicek, B., T. Aydogmus, and Y. Sun, "A basic study on artificial aging in Mg-10Al12Si+ 1Pb alloy", Materials Research Express, 7, 016588, 2020

[18]. Zhu, L., et al., "Multiscale design of $\alpha$-Al, eutectic silicon and Mg2Si phases in Al-Si-Mg alloy manipulated by in situ nanosized crystals", Materials Science and Engineering: A, 802, 140627, 2021

[19]. Koç, E., "Corrosion behaviour of as cast $\beta-\mathrm{Mg} 17 \mathrm{Al} 12$ phase in $3.5 \mathrm{wt} \% \mathrm{NaCl}$ solution", Acta Physica Polonica A, 135, 881-883, 2019

[20]. Sun, Y. and H. Ahlatci, "Mechanical and wear behaviors of Al-12Si-XMg composites reinforced with in situ Mg2Si particles", Materials \& Design, 32, 2983-2987, 2011

[21]. Zhang, J., et al., "Microstructure and mechanical properties of in situ Al-Mg2Si composites", Materials science and technology, 16, 913-918, 2000

[22]. Feng, Y. and T. Zhang, "Determination of fracture toughness of brittle materials by indentation", Acta Mechanica Solida Sinica, 28, 221-234, 2015 